\title{
Otimização do procedimento de colagem de braquetes ortodônticos utilizando um recipiente fotoprotetor: passo a passo
}

\section{Optimization of the bonding procedure of orthodontic brackets using a photoprotective vessel: step-by-step}

\author{
Mirella Silvestre Lummertz* \\ Natália Ferraz Piller* \\ Paulo Eduardo Guedes Carvalho*** \\ Fernando César Torres ${ }^{* * * *}$ \\ Paulo Francisco Cesar ${ }^{* * * *}$ \\ Lucas Hian da Silva***
}

\begin{abstract}
Resumo
A resina composta fotoativável é usualmente utilizada para o procedimento de colagem de braquetes ortodônticos. No entanto, seu uso requer cuidados antes da fotoativação, pois sua polimerização pode ocorrer precocemente por outras fontes de luz, que não a de um fotoativador dentário (e.g., luz ambiente). Foi idealizado um recipiente fotoprotetor que permite o armazenamento temporário do conjunto de pinças com os braquetes preparados com resina em sua base, evitando o processo de polimerização da resina antes do momento desejado. Objetivo: este estudo tem como objetivo apresentar uma descrição detalhada do procedimento de colagem de braquetes ortodônticos estéticos cerâmicos, quando se utiliza um recipiente fotoprotetor para otimizar o atendimento. Relato de caso: paciente do sexo feminino, 24 anos de idade, submeteu-se ao tratamento ortodôntico em clínica particular. Foram utilizados braquetes ortodônticos autoligados, cerâmicos de alumina policristalina. A colagem dos braquetes foi realizada na arcada inferior de maneira tradicional, porém se fez uso de um recipiente fotoprotetor (protótipo) para otimizar o procedimento. O recipiente teve como finalidade principal o armazenamento temporário de braquetes ortodônticos apreendidos em pinças ortodônticas, já com resina composta para colagem em suas
\end{abstract}

bases. Concluiu-se a instalação do aparelho ortodôntico com a colocação de um arco ortodôntico redondo $\mathrm{Ni}$-Ti 0,014". Considerações finais: a utilização do recipiente fotoprotetor mostrou-se clinicamente eficaz e apresentou um bom resultado final da satisfação tanto do profissional quanto do paciente. O seu uso foi capaz de reduzir o tempo de cadeira do paciente durante o procedimento e impediu a polimerização precoce da resina composta de colagem utilizada.

Palavras-chave: Braquetes ortodônticos. Polimerização. Resinas compostas.

\section{Introdução}

Com o aumento da demanda estética para que os aparelhos ortodônticos sejam cada vez mais translúcidos, as resinas compostas fotopolimerizáveis de colagem estão sofrendo maior influência da exposição à luz ambiente. ${ }^{1}$ A resina utilizada para colagem dos braquetes, ao ser exposta à luz ambiente, acaba por sofrer uma rápida polimerização precoce, uma vez que o braquete estético não atua mais como uma barreira opaca para proteger o material

Mestre em Ortodontia, Universidade Cidade de São Paulo (Unicid), Departamento do Mestrado em Odontologia, São Paulo, SP, Brasil.

Graduanda em Odontologia Universidade Cidade de São Paulo (Unicid) Departamento do Mestrado em Odontologia São Paulo, SP, Brasil.

Doutor em Ortodontia, Professor associado da Universidade Cidade de Sáo Paulo (Unicid), Departamento do Mestrado em Odontologia, São Paulo, SP Brasil.

Doutor em Ortodontia, Professor associado da Universidade Cidade de São Paulo (Unicid), Departamento do Mestrado em Odontologia, São Paulo, SP, Brasil.

***** Doutor em Materiais Dentários, Professor Associado da Universidade de São Paulo (USP), Departamento de Biomateriais e Biologia Oral, São Paulo, SP, Brasil. Doutor em Biomateriais e Biologia Oral, Professor Associado da Universidade de São Paulo (USP), Departamento de Biomateriais e Biologia Oral, São Paulo, SP, Brasil. 
de colagem da luz, como acontecia com o braquete metálico. Diversas fontes luminosas podem ocasionar a polimerização precoce da resina composta de colagem. Entre elas, podem ser citadas as principais encontradas atualmente: i) luz fluorescente do teto; ii) luz do refletor; e iii) luz solar externa (janelas)., ${ }^{2,3}$

Geralmente, o procedimento de colagem ortodôntica de braquetes em duas arcadas pode ter uma duração clínica aproximada de 30 minutos. ${ }^{4}$ Esse tempo pode aumentar quando se faz uso de braquetes estéticos translúcidos (e.g., cerâmicos), pois a técnica se torna mais sensível devido à facilidade que a luz ambiente tem em causar a polimerização precoce da resina de colagem. Por esse motivo, preconiza-se a preparação de cada braquete com resina composta em sua base de maneira individual, para ser feita a colagem imediata. ${ }^{5}$

A polimerização precoce da resina composta de colagem ortodôntica pela luz ambiente pode causar uma série de complicações, ${ }^{2,3}$ como: diminuição da fluidez do material resinoso, diminuição da força de união do braquete ao dente suporte e mau posicionamento do braquete durante o procedimento de colagem. A perda de fluidez da resina composta de colagem ocorre aproximadamente um minuto após a exposição à luz ambiente, devido à polimerização parcial do material. ${ }^{6}$ Tal fato impede a preparação prévia de mais de um braquete antes de se proceder à instalação dos aparelhos, pois a polimerização parcial da resina de colagem aconteceria por ação da luz ambiente. Adicionalmente, a falha por soltura dos braquetes ortodônticos nos dentes suportes, devido à baixa adesão, apresenta relação com a polimerização precoce do material de colagem. ${ }^{7} \mathrm{~A}$ resina composta, quando parcialmente polimerizada pela luz ambiente, encontra maior dificuldade para penetrar nas retenções da base do braquete, diminuindo a adesão. Também, a resina composta, quando polimerizada precocemente, de maneira parcial, pode sofrer prejuízos nas suas propriedades biológicas, físicas e mecânicas. ${ }^{6}$

Um recipiente que proteja a entrada de luz, para permitir a acomodação das pinças pré-organizadas com resina composta disposta na base dos braquetes, torna-se uma proposta relevante para otimizar o tempo clínico durante o procedimento de colagem e diminuir custos e falhas por polimerização precoce do material de colagem. Para tanto, a preparação prévia dos braquetes em pinças com resina em sua base diminui o risco de desperdícios de material de colagem, pois a preparação antecipada permite maior controle da quantidade de resina a ser colocada (i.e., uso de uma porção ideal). A utilização do recipiente fotoprotetor auxilia profissionais a otimizar o tempo de atendimento clínico, uma vez que os procedimentos de colagem de aparelhos ortodônticos podem ser preparados anteriormente ao início do atendimento e permanecer protegidos da ação prejudicial da luz ambiente nas resinas compostas de colagem já dispostas nas bases dos braquetes.
Este estudo teve como objetivo principal apresentar uma descrição detalhada do procedimento de colagem de braquetes ortodônticos estéticos cerâmicos quando se utiliza um recipiente fotoprotetor para otimizar o atendimento clínico.

\section{Relato de caso}

A descrição apresentada a seguir mostra de maneira sistemática e detalhada o procedimento de colagem de braquetes ortodônticos na arcada inferior de um paciente do sexo feminino, 24 anos de idade, que se submeteu ao tratamento ortodôntico. Ao final do procedimento de colagem, foi feita a instalação do arco ortodôntico correspondente às etapas de alinhamento e nivelamento. A colagem dos braquetes foi realizada com o auxílio de um recipiente fotoprotetor (protótipo, patente BR2020170145315, Figura 1) desenvolvido para otimizar o procedimento. Figura 1 - Imagem representativa do recipiente fotoprotetor desen-
volvido para otimizar o procedimento de colagem de bra-
quetes

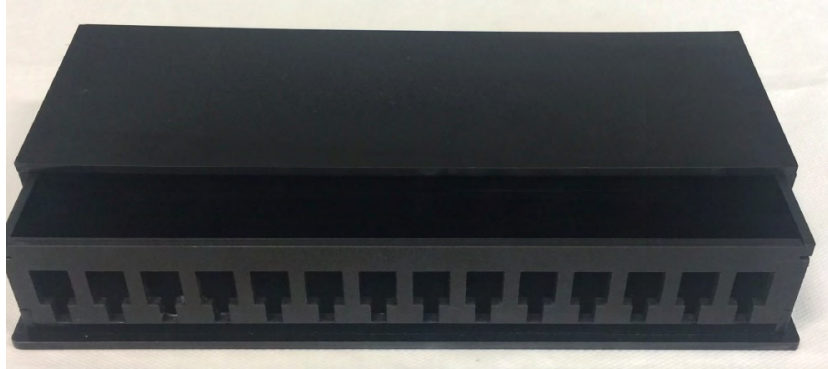

Fonte: acervo pessoal.

\section{Detallhes do recipiente fotoprotetor}

Simplificadamente, o recipiente fotoprotetor consiste em uma caixa da cor preta cujo interior protege completamente da luz. A caixa apresenta as seguintes dimensões: $6 \mathrm{~cm}$ de altura, $20 \mathrm{~cm}$ de largura e $5 \mathrm{~cm}$ profundidade; presenta também 14 nichos em sua parte frontal, para o posicionamento dos conjuntos de pinças/braquetes. Os nichos têm dimensões de $1 \mathrm{~cm}$ de largura e $1 \mathrm{~cm}$ de altura, e cada nicho tem um entalhe que permite o travamento individual de uma pinça. $\mathrm{O}$ recipiente fotoprotetor tem a sua porção superior removível, dessa maneira facilitando a sua higienização e a recuperação de algum braquete que venha a se soltar acidentalmente. Sua finalidade principal é o armazenamento temporário de braquetes ortodônticos previamente apreendidos em pinças ortodônticas, já com resina composta para colagem em suas bases. $\mathrm{O}$ material utilizado na fabricação do recipiente ortodôntico fotoprotetor foi o polímero de polipropileno com opacidade total, um tipo de plástico autoclavável. 


\section{Preparação do material para o procedimento}

Neste procedimento, foram utilizados braquetes ortodônticos autoligados, cerâmicos de alumina policristalina (Truklear, Forestadent, Alemanha). Os braquetes cerâmicos foram retirados das embalagens, colocados em uma bandeja de maneira ordenada para realização do procedimento de colagem nos dentes. A mesa clínica foi previamente preparada para iniciar o procedimento, contendo: bandeja com pinças ortodônticas com os braquetes fixados em suas extremidades, ácido fosfórico 35\% (Ultra-Etch, Ultradent, Brasil), adesivo dentário (Adper Single Bond 2, 3M ESPE, Brasil), microaplicador descartável (Brush, KG Sorensen, Brasil) e resina composta fotoativável na cor A2 (Z100, 3M ESPE, Brasil). Ao lado, foi posicionado o aparelho fotopolimerizador de diodo emissor de luz (LED; Radii-Cal, SDI Limited Bayswater, Austrália), com $1.200 \mathrm{~mW} /$ $\mathrm{cm}^{2}$ de densidade de potência e o arco ortodôntico redondo Ni-Ti 0,014" (Biocosmetic, Forestadent, Alemanha), que foi utilizado após a colagem dos braquetes. $\mathrm{O}$ recipiente fotoprotetor utilizado para otimizar o procedimento de colagem dos braquetes foi posicionado na mesa clínica com sua tampa devidamente fechada, para evitar a entrada de luz em seu interior.

\section{Preparação dos braquetes}

Uma pequena porção de resina composta foi retirada da embalagem com uma espátula de inserção $\mathrm{n} \square 1$ (S.S. White - Duflex, Brasil), para assim ser depositada uma camada fina e homogênea na base de cada um dos braquetes ortodônticos já fixados em pinças ortodônticas. À medida que a resina composta era disposta nas bases dos braquetes, os conjuntos pinça/braquete eram posicionados imediatamente, de maneira sequencial, nos nichos do recipiente fotoprotetor (Figura 2).

Figura 2 - Imagem representativa do posicionamento dos conjuntos pinça/braquete preparados no recipiente fotoprotetor

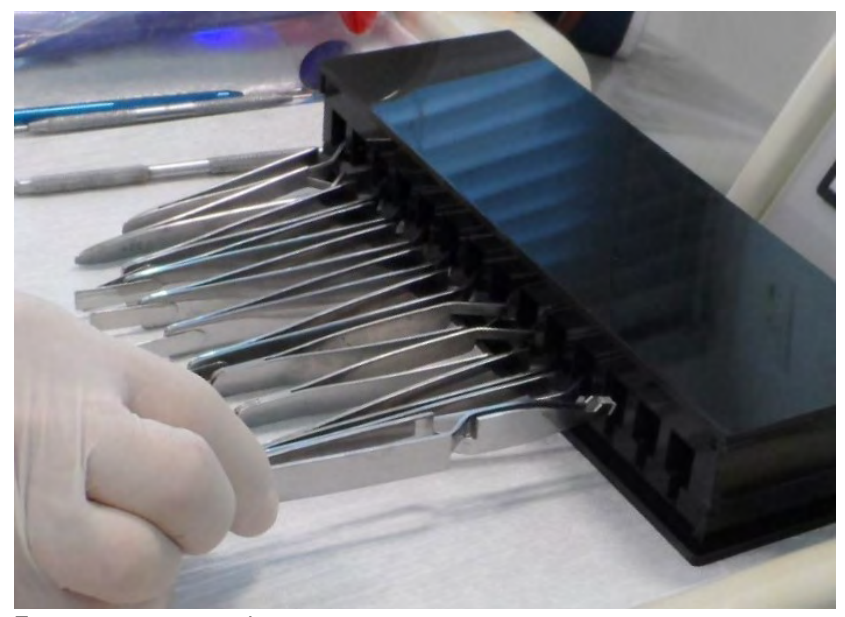

Fonte: acervo pessoal.
Os conjuntos pinça/braquete ficaram protegidos da luz no interior do recipiente fotoprotetor, de maneira que um braquete não tivesse contato com o outro (Figura 3), evitando assim o deslocamento das pinças.

Figura 3 - Imagem representativa da posição dos conjuntos pinça/ braquete no interior do recipiente fotoprotetor

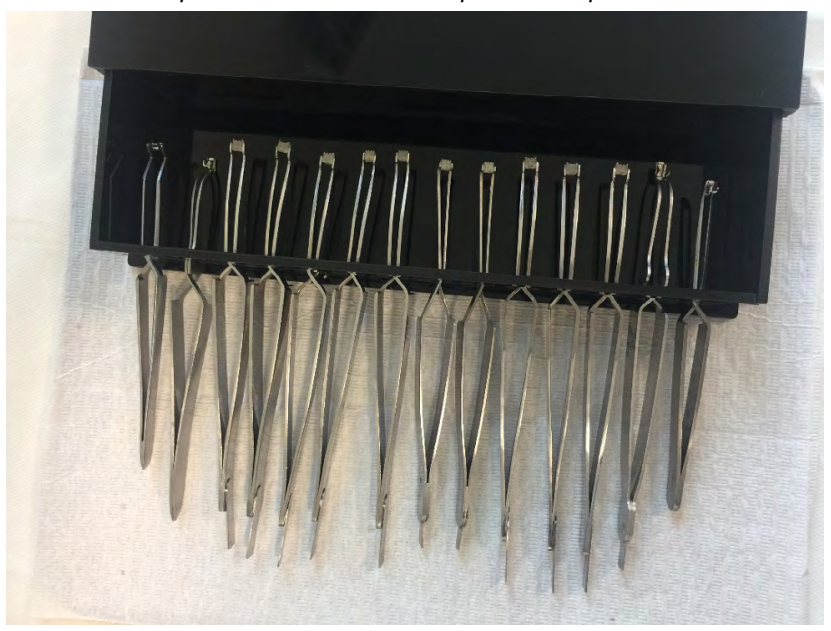

Observação: a abertura do recipiente não deve acontecer durante o procedimento.

Fonte: acervo pessoal.

\section{Procedimento de colagem}

Inicialmente, foi feita a profilaxia com pedra-pomes e água em todos os elementos dentários, por meio do uso de escova giratória tipo Robinson e taça de borracha (Preven Engenharia e Medicina do Trabalho Ltda., Brasil). A profilaxia inicial teve como objetivo a remoção de remanescentes de biofilme dentário e da película adquirida do esmalte. Após a profilaxia, foi feita a lavagem das superfícies dentárias com jatos de água e ar, para a remoção dos remanescentes de material aderido.

Para que todo o procedimento de colagem ocorresse adequadamente e livre de contaminação por saliva, fez-se a colocação de um afastador labial equipado com 2 sugadores (Nola Dry, Ortho Technology, EUA) no paciente. Com as superfícies dos dentes secas por jatos de ar, iniciou-se o procedimento adesivo para a colagem dos braquetes. O condicionamento ácido foi feito apenas em regiões específicas das faces vestibulares dos dentes, que seriam destinadas às colagens dos braquetes ortodônticos.

$\mathrm{O}$ procedimento adesivo seguiu os seguintes parâmetros:

1. condicionamento ácido de regiões específicas nas superfícies do esmalte dentário por 20 segundos com ácido fosfórico $35 \%$;

2. lavagem das áreas contendo ácido fosfórico e secagem, para remoção do excesso de umidade;

3. aplicação do adesivo nas superfícies condicionadas dos dentes com um microaplicador descartável; 
4. evaporação dos solventes do sistema adesivo com leves jatos de ar por 10 segundos;

5. fotopolimerização do sistema adesivo nas superfícies dos dentes por 20 segundos.

As pinças contendo os braquetes ortodônticos, que foram previamente preparados com resina, foram retiradas sequencialmente do recipiente fotoprotetor e posicionadas nas faces vestibulares dos dentes correspondentes. Deve-se destacar que, apenas quando todo o procedimento de colagem de um braquete era finalizado, se procedia à retirada de outro conjunto pinça/braquete do recipiente fotoprotetor.

O procedimento de colagem dos braquetes seguiu a seguinte sequência:

1. remoção do conjunto pinça/braquete do recipiente fotoprotetor (Figura 4);

Figura 4 - Imagem representativa da remoção do conjunto pinça/braquete do recipiente fotoprotetor para ser levado à boca do paciente

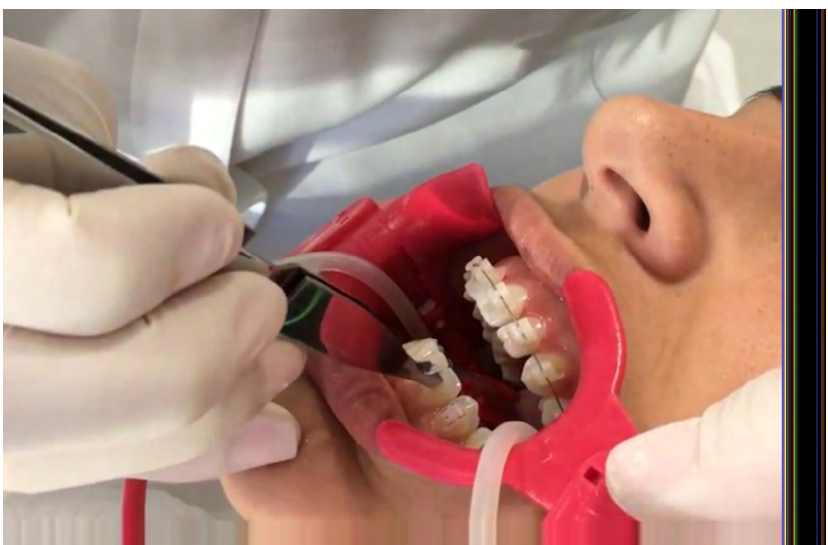

Fonte: acervo pessoal.

2. posicionamento do braquete na superfície vestibular do dente que foi condicionada e recebeu sistema adesivo (Figura 5);

Figura 5 - Imagem representativa do posicionamento do braquete na superfície vestibular do dente que foi condicionada e recebeu sistema adesivo

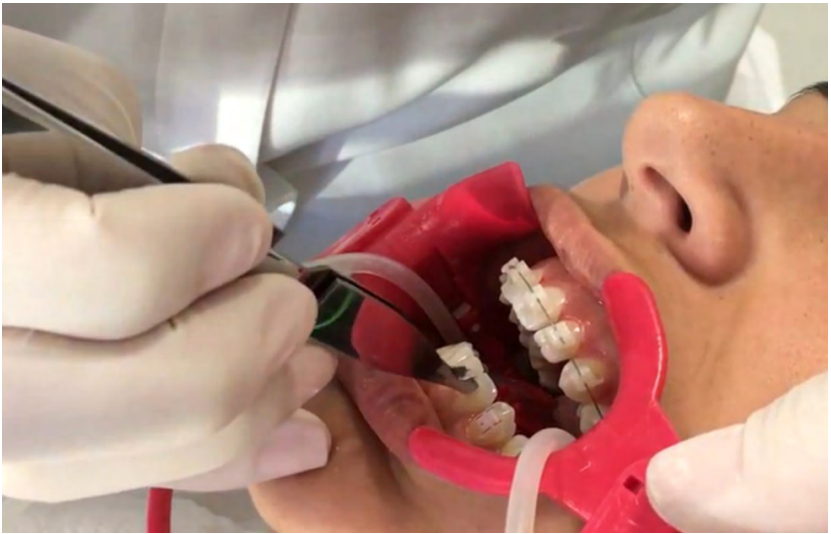

Fonte: acervo pessoal.
3. remoção do excesso de resina composta ao redor do braquete;

4. fotopolimerização da resina composta de colagem por 40 segundos com equipamento de LED posicionado na região central do braquete (Figura 6).

Figura 6 - Imagem representativa da fotopolimerização da resina composta de colagem com o equipamento de LED posicionado na região central do braquete

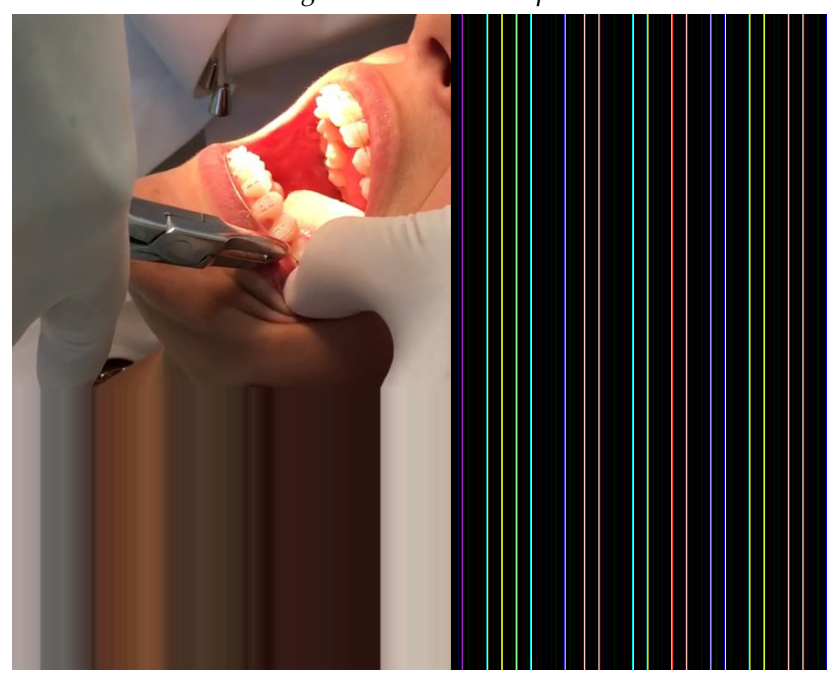

Fonte: acervo pessoal.

Finalizado o posicionamento e a polimerização de todos os braquetes ortodônticos, foi feita a instalação do arco ortodôntico com stop na região dos molares (Figura 7).

Figura 7 - Imagem representativa da instalação do arco ortodôntico redondo $\mathrm{Ni}$-Ti $0,014^{\prime \prime}$

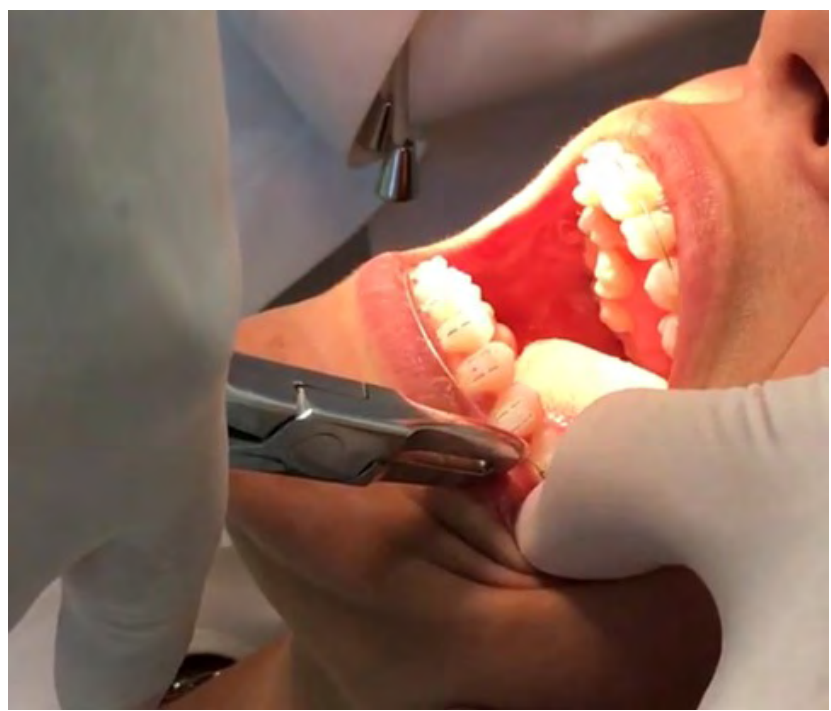

Fonte: acervo pessoal. 


\section{Discussão}

O recipiente fotoprotetor foi projetado visando a acomodar temporariamente diversos braquetes contendo em suas bases resina composta para colagem, já previamente apreendidos em pinças ortodônticas. Os braquetes ficam posicionados lado a lado no interior do recipiente e protegidos contra a ação de luzes do ambiente externo., ${ }^{1,2}$ Dessa maneira, evita-se a polimerização precoce da resina composta, que poderia interferir negativamente na instalação dos braquetes ortodônticos. ${ }^{2,3}$

A vantagem principal de se utilizar o recipiente fotoprotetor é a otimização do procedimento pelo profissional, que vai conseguir atuar com mais rapidez e organização. O uso do recipiente possibilita ao profissional deixar vários braquetes preparados com resina composta para a colagem, montados em pinças ortodônticas. Adicionalmente, essa montagem antecipada do conjunto pinça/braquete diminui a preocupação com perdas de material de colagem, pois tem-se mais tempo para a disposição da resina, uma vez que o preparo pode ser feito antes de o paciente estar sendo atendido. A redução de custos e, principalmente, de tempo nas consultas traz benefícios para pacientes e ortodontistas. De maneira geral, observa-se um ganho de 10 a 15 minutos em um procedimento de colagem de braquetes ortodônticos em uma arcada, que pode chegar a 30 minutos, considerando as duas arcadas. ${ }^{4}$ Esse dado torna-se mais relevante, quando se observa o ganho de tempo em um dia clínico, em que acontecem diversas instalações de aparelhos ortodônticos agendadas.

O material utilizado na fabricação do recipiente fotoprotetor foi o polímero de polipropileno. É um material de baixo custo, que permite a sua autoclavagem, ${ }^{8}$ para possibilitar a esterilização do recipiente fotoprotetor e a eliminação do risco de infecção cruzada. ${ }^{9}$

Por fim, ainda acredita-se que estudos experimentais devem ser desenvolvidos para validar a eficiência do recipiente fotoprotetor em proteger $o$ material resinoso de uma polimerização precoce e, também, quantificar de maneira não empírica o ganho em tempo clínico.

\section{Considerações finais}

A utilização inicial do equipamento mostrou-se extremamente eficiente e com bom resultado final de satisfação tanto do profissional quanto do paciente.

\section{Abstract}

The photo-activated resin composite is usually used for the bonding procedure of orthodontic brackets. However, their use requires caution prior to photoactivation, as their polymerization may occur early by light sources other than a dental photoactivator (e.g. ambient light). A photoprotective vessel has been developed to allow temporary storage of the clamps assembly with the resin-prepared brackets, avoiding the polymerization process of the resin prior to the desired moment. Objective: this study purpose was to present a detailed description of the bonding procedure of ceramic orthodontic brackets when using a photoprotective vessel to optimize care. Case report: a 24-year-old female patient underwent orthodontic treatment in a private practice. Orthodontic brackets of polycrystalline alumina ceramics were used for treatment. Bracket bonding was performed in the lower arch in the traditional manner, however a photoprotective vessel (prototype) was used to optimize the procedure. The main purpose of the vessel was the temporary storage of orthodontic brackets-clamps assembly, already with composite resin for bonding in their bases. The installation of the orthodontic appliance was finished with the placement of a 0.014" round $\mathrm{Ni}-\mathrm{Ti}$ orthodontic arch. Final considerations: the use of the photoprotective vessel was clinically effective and with a good end result in both professional and patient satisfaction. Its use was able to reduce the patient's chair time during the procedure and prevented the early polymerization of the bonded composite resin used.

Keywords: Orthodontic brackets. Polymerization. Composite resins.

\section{Referências}

1. 'Russell JS. Current Products and Practice. J Orthod 2005; 32(2):146-63.

2. Miletić V, Stanković TS, Stašić J. Sensitivity of Composite Materials to Ambient Light and Clinical Working Time. Serbian Dental J 2012; 59(4):190-7.

3. Kohda N, Iijima M, Ito S, Takeshi M, Takashi S, Itaru M. Effects of exposure time and bracket position adjustment under ambient light before light-curing of composite resin adhesives on bracket bond strength to enamel. Dental J Health Sci Uni Hokkaido 2015; 34(1):21-6.

4. Lee M, Kanavakis G. Comparison of shear bond strength and bonding time of a novel flash-free bonding system. Angle Orthod 2016; 86(2):265-70.

5. Cai Z, Iijima M, Eliades T, Brantley W. 10 - Frequent handling mistakes during bonding. In: Eliades T, Brantley WA. Orthodontic Applications of Biomaterials. England: Woodhead Publishing; 2017. p. 171-177.

6. Dlugokinski MD, Caughman WF, Rueggeberg FA. Assessing the effect of extraneous light on photoactivated resin composites. J Am Dent Assoc 1998; 129(8):1103-9.

7. Thiyagarajah S, Spary DJ, Rock WP. A clinical comparison of bracket bond failures in association with direct and indirect bonding. J Orthod 2006; 33(3):198-204.

8. Rutala WA, Weber DJ. Disinfection and sterilization: An overview. Am J Infect Control 2013; 41(5):S2-S5.

9. Manzoli TM, Souza IA, Nascimento SSV, Morais JMP, Umezawa M. Vantagens da utilização de embalagens de polipropileno para esterilização de materiais odontológicos. Rev Odontol UNESP 2017; 460.

\section{Endereço para correspondência:}

Lucas Hian da Silva

Faculdade de Odontologia da Universidade Cidade de São Paulo

Rua Cesário Galeno, 448/475, Tatuapé

03071-000, São Paulo, SP, Brasil

Telefone: (11) 2178-1366

E-mail:cdhian@gmail.com

Recebido: 01/06/18. Aceito: 27/08/18. 